\title{
La Guerra del Paraguay en el territorio íntimo: el diario del historiador Juan E. O'Leary (1907-1937)
}

\author{
Liliana María Brezzo* \\ Recibido: 30 de octubre de 2019 \\ Dictaminado: 20 de mayo de 2020 \\ Aceptado: 30 de agosto de 2020
}

\section{RESUMEN}

Este trabajo comunica los resultados preliminares de un estudio sobre los tres primeros cuadernos del diario íntimo del historiador paraguayo Juan E, O'Leary (1879-1969) siguiendo la marca de la Guerra del Paraguay. Durante su longeva vida, O'Leary construyó una interpretación del conflicto bélico de cuño nacionalista que caló en vastos sectores de la sociedad paraguaya, de modo que su discurso histórico no fue sólo informativo, en el sentido de comunicar hechos y eventos del pasado, sino también performativo, puesto que edificó realidades en la memoria colectiva. El manuscrito, recientemente recuperado de su extenso fondo documental, comprende un total de diecisiete cuadernos y abarca los años 1907 y 1960. El supuesto que enhebra la atenta lectura que se ha producido hasta ahora es que la escritura íntima del historiador paraguayo es una fuente apreciable para penetrar en las distintas formas en las que construyó

* Consejo Nacional de Investigaciones Científicas y Técnicas - Instituto de Estudios Históricos, Económicos, Sociales e Internacionales - Nodo Instituto de Historia - Pontificia Universidad Católica Argentina, Rosario, Argentina. Correo electrónico: 1ilianabrezzo@gmail.com 
el acceso al conocimiento del pasado, y, en particular, contribuye a dotar de una mayor inteligibilidad el extenso proceso de gestación de su obra histórica sobre el conflicto bélico.

Palabras clave: Guerra del Paraguay, discurso histórico, diario intimo, historiadores paraguayos.

\title{
The Paraguayan War in intimate territory: the journal of the historian Juan E. O'Leary (1907-1937)
}

\begin{abstract}
This work communicates the preliminary results of a study on the first three notebooks of the private diary of the Paraguayan historian Juan E, O'Leary (1879-1969) following the mark of the Paraguayan War. During his long life, O'Leary built an interpretation of the nationalist war conflict that permeated vast sectors of Paraguayan society, so that his historical discourse was not only informative, in the sense of communicating past events and events, but also performative, since it built realities in the collective memory. The manuscript, recently recovered from its extensive documentary collection, comprises a total of seventeen notebooks and covers the years 1907 and 1960. The assumption that threads the careful reading that has occurred so far is that the intimate writing of the Paraguayan historian is an appreciable source to penetrate the different ways in which he built access to knowledge of the past, and, in particular, contributes to making the extensive process of gestation of his historical work on the warlike conflict more intelligible.
\end{abstract}

Key words: Paraguay War, historical speech, intimate diary, Paraguay historians.

\section{INTRODUCCIÓN}

Tace ciento cincuenta años, entre 1864 y 1870, Argentina, Uruguay, Brasil

y Paraguay protagonizaron el conflicto más sangriento de Sudamérica del siglo diecinueve. La denominada Guerra del Paraguay, Guerra de la Triple Alianza, Guerra Grande o Guerra Guasu fue un enfrentamiento bélico de alta densidad por su duración, por la sobremortalidad y por sus efectos en el funcionamiento de las sociedades. Las trayectorias interpretativas del conflicto en los cuatro países beligerantes han sido tumultuosas; en particular, el estudio acerca de cómo en el Paraguay se procesó la memoria de la guerra aparece, hasta el presente, como una cuestión controversial. En ese contexto emergió, a comienzos del siglo veinte, la figura del historiador paraguayo Juan Emiliano 
O’Leary (1879-1969). Conocido como "el vocero del lopismo", "el cantor de las glorias nacionales", "el reivindicador", en el transcurso de su intensa y longeva vida construyó una interpretación de la guerra que convirtió a la derrota en la victoria del "paraguayo más inmortal", el presidente Mariscal Francisco Solano López; al cataclismo bélico en una "epopeya nacional" y al pueblo paraguayo en el "invicto vencido" porque jamás se rindió durante los cinco años que duraron las acciones militares. De tal manera, esta visión caló en vastos sectores de la sociedad paraguaya que se podría sostener que su discurso histórico no fue sólo informativo, en el sentido de comunicar hechos y eventos del pasado, sino también performativo, puesto que edificó realidades en la memoria colectiva.

El archivo personal de O'Leary, recientemente recuperado, es uno de los más abundantes del siglo veinte en Paraguay. La conversación mantenida a distancia con amigos, colegas y rivales políticos dio origen a un voluminoso acervo epistolar comprendido entre los años 1899 y 1969. Junto a la práctica epistolar O’Leary cultivó la redacción de un diario íntimo que reunió en diecisiete cuadernos comprendidos entre 1907 y 1960. Dentro de las múltiples temáticas que circulan en este extenso manuscrito, como el protagonismo de su familia, la vida política paraguaya, las amistades, los avatares de su trayectoria profesional, los espacios de actuación pública y las visiones de los países en los que vivió, es la memoria (y la escritura) de la Guerra del Paraguay la temática que lo atraviesa más profusamente. Este trabajo se posa en los tres primeros cuadernos del diario íntimo de Juan E. O'Leary siguiendo esa marca. El supuesto que enhebra el estudio es que su escritura íntima es una fuente apreciable para penetrar en las distintas formas en las que construyó el acceso al conocimiento del pasado, y que contribuye a dotar de una mayor inteligibilidad el extenso proceso de gestación de su obra histórica sobre el conflicto bélico.

Un diario íntimo puede definirse como aquella narración en prosa de un sujeto real que por mediación del lenguaje se construye en el texto, al tomar su propia existencia cotidiana como sustancia y espacio de la escritura, permitiéndole interrogarse sobre sí y por el que puede acceder al conocimiento de sí. Es a la vez un documento y un testimonio; testimonio de una forma de vida y documento de trabajo sobre la obra de quien lo escribe. El diario íntimo, la quintaesencia de la literatura autobiográfica, en opinión de Anna Caballé, ha sido considerado históricamente una modalidad literaria heterogénea y ambigua, ya que en su origen no está destinado a salir de los confines de su secreto personal. ${ }^{1}$ Sin embargo, Alan Girard extrae dos rasgos importantes que encierran ciertas paradojas respecto a la privacidad, cuando afirma que el

1 Caballé, Narcisos de tinta. Ensayos sobre la autobiografia en lengua castellana. Siglos XIX y XX, Málaga, 1995. 
diarista escribe para ser leído, y el diario sólo puede ser sincero, "sinceridad intrínseca del diario íntimo" a condición de ser un diario que no es publicado sino hasta la muerte del escritor. ${ }^{2}$ Para Girard, una singularidad que distingue al diario de las otras formas de escribir el yo descansa en que los acontecimientos son consignados no en sí mismos, sino que son una ocasión para el autor de reflexionar sobre sí mismo, de provocar un sentimiento o un pensamiento, de aclarar un aspecto de esos acontecimientos. Se trata, pues, de una práctica secreta y, a menos que sea publicado, nada sabemos de su existencia, a no ser que el manuscrito aparezca, como en este caso, en el archivo personal del historiador. Por su parte, Manuel Hierro menciona tres dominios que balizan el estudio del diario íntimo: el tiempo presente en el que (se) escribe el diarista, la intimidad y la identidad personal. ${ }^{3}$ A través de estas coordenadas es posible recuperar de qué modo el diarista construye la imagen de sí y del mundo que le rodea - el pasado - tomando conciencia de sí mismo.

Los estudios dedicados a escrutar textos autorreflexivos desde el punto de vista de la figura del historiador revisten un creciente interés, aunque, de momento, no sean cuantiosos. Jaume Aurell, por ejemplo, analiza en sendos estudios actuales un abigarrado conjunto de autobiografías académicas de historiadores, en los que abundan referencias a lo que Pierre Nora llamó “ego historia" o escrituras del yo, y en los que sostiene que ese tipo de auto-escritura - en este caso autobiografías destinadas de historiadores dirigidas a la esfera pública- no sólo son textos en los que sus autores comunican eventos de su trayectoria profesional que se pueden conocer, sino que también comportan hechos intelectuales y pueden transformar realidades disciplinares, académicas y epistemológicas, es decir, aportar nuevas claves para comprender la evolución de la disciplina histórica y contribuir a generar nuevas transformaciones en los paradigmas que sustentan teóricamente las tendencias historiográficas. ${ }^{4}$ Por su parte, Ignacio Peiró Martín ha mostrado por qué el gusto de los historiadores por narrar los recuerdos de su vida y por otorgar significado a sus experiencias profesionales se ha extendido a tal punto que se ha convertido en un fenómeno característico de la producción histórica actual. ${ }^{5}$ Otros trabajos dedicados a analizar diferentes expresiones del denominado espacio biográfico — cartas, autobiografías, apuntes íntimos - llaman la atención sobre cómo el itinerario personal de un historiador no es un hecho accidental en su carrera profesional,

2 Girard, Le journal intime, Paris, 1993.

3 Hierro, "La comunicación callada de la literatura: reflexión teórica sobre el diario íntimo", pp. 103-127.

$4 \quad$ Aurell, "Del logocentrismo a la textualidad: la autobiografía académica como intervención historiográfica”, pp. 193-222 y La historia de España en primera persona. Autobiografías de historiadores hispanistas, Barcelona, 2012.

5 Peiró Martín, "La contemplación de Narciso. La "vocación autobiográfica" de los historiadores, pp. 361-388. 
sino que, de un modo bastante complejo, condiciona el entero proceso de la investigación, de la elección de los temas y de sus enfoques. ${ }^{6}$ En general, coinciden en las ventajas que ofrecen las distintas formas de auto escritura para el estudio de la subjetividad y de la sociabilidad entre hombres y mujeres abocados a las letras o la cultura, puesto que contribuyen a develar la intimidad de su pensamiento, de sus emociones; ${ }^{7}$ permiten reconstruir el mapa de sus relaciones intelectuales, así como también las vías de circulación y distribución de los textos dirigidos a la esfera pública ${ }^{8}$ y hacen visible el vínculo estrecho entre vida y escritura. ${ }^{9}$ De modo que, en el contexto de este trabajo, hacer foco en las escrituras privadas puede producir conocimiento en una doble dirección. Por un lado, en cuanto al análisis del historiador y su evidente dimensión social, es decir, comprenderlo mejor en su historia y la historia que él ha narrado ${ }^{10}$ $y$, en otro sentido, percibir mejor hasta qué punto ha sido moldeado por el contexto en el que transcurrió su actuación profesional y la aparición de su producción histórica. ${ }^{11}$

\section{Los REgistros ESCRITURARIOS DE JUAN E. O'LEARY}

Las principales obras históricas en las que el polifacético Juan O’Leary dio a conocer su visión sobre la Guerra del Paraguay fueron: Nuestra Epopeya (1919), El Mariscal Solano López (1920 y 1925), El libro de los héroes. Páginas históricas de la guerra del Paraguay (1922) y El Centauro de Ybycui. Vida heroica del general Bernardino Caballero en la Guerra del Paraguay (1929). Además de estos libros, figuran folletos y numerosos artículos en la prensa que han sido tan sólo recientemente objeto de la atención por parte de estudiosos de los procesos de la escritura de la historia en Paraguay. Entre las novedades figuran, por ejemplo, la recuperación de la serie de artículos titulada Recuerdos de Gloria que O'Leary divulgó en el diario asunceno La Patria en el año 1902, dedicada a evocar las acciones militares de la guerra, ${ }^{12}$ y de los textos de la trascendente Polémica sobre la historia del Paraguay que mantuviera con el

6 Aurell, "Textos autobiográficos como fontes historiográficas: relendo a Fernand Braudel e Anne Kriegel”, pp. 340-36; Peluffo y Maíz, “Afectos, redes y epistolarios”, pp. 132-139; Costa Motta-Souza Fredrigo, "Escritas de sí nas Américas”, pp. 1-9.

7 Bouvet, La cultura epistolar, Buenos Aires, 2006.

8 Myers, "El epistolario como conversación humanista: la correspondencia intelectual de Alfonso Reyes y Genaro Estrada (1916-1939)", pp. 53-70.

9 Batticuore, "La vida en las cartas: Ricardo Palma entre escritoras", pp. 161-166.

10 Aurell, La historia de España en primera persona. Autobiografias de historiadores hispanistas, 2013.

11 Halperin Donghi, Son memorias, Buenos Aires, 2008; Saitta, "Son memorias, el autobiográfico juego de un tímido", pp. 155-167.

12 Scavone Yegros (ed.), Juan E. O'Leary. Recuerdos de Gloria, 2008. 
reconocido intelectual Cecilio Báez (1862-1941) entre los años 1902 y $1903 .{ }^{13}$ Se ha dado a conocer también una primera compilación de su bibliografía — que deberá completarse_-, que permite remontar sus publicaciones al año 1898, donde habría iniciado su andadura intelectual con una poesía titulada "24 de Mayo" (en memoria de la batalla de Tuyutí), publicada en la Revista del Instituto Paraguayo, hasta el año 1920 en el que figuran dos artículos en la revista cultural Guarania bajo los títulos "El héroe de los lanchones" y "Pane". ${ }^{14}$ La reciente catalogación de la biblioteca de O’Leary preparada y publicada por la Biblioteca Nacional del Paraguay constituye el esfuerzo más actual dirigido a restituir su trayectoria intelectual. ${ }^{15}$

Ya se ha apuntado que el archivo de O'Leary reúne uno de los cuerpos paraguayos de correspondencia más abundantes de la primera mitad del siglo veinte, importante no únicamente por la cartografía de las relaciones familiares, de amistad e intelectuales que permite reconstruir, sino también por el propio contenido de las cartas, en las cuales los interlocutores se extienden sobre sus emociones, sus posturas políticas, las interpretaciones del pasado, los proyectos personales y profesionales. ${ }^{16}$

El robusto acervo de cartas se explica, en parte, por la extensa trayectoria político cultural de O'Leary, de sus actividades como periodista (a partir de su incorporación, en 1900, como columnista del diario La Patria), como diplomático (fue Encargado de Negocios en España, 1925-1929; Ministro Plenipotenciario en España, 1936; Ministro Plenipotenciario en Italia, 1936-1937 y 1947-1948 y Embajador ante la Santa Sede, 1951-1954) y, fundamentalmente, como historiador.

O'Leary integró el grupo de intelectuales paraguayos que se conoce como la Generación del 900. Nacidos en su mayoría en la primera década de la posguerra, entre 1870 y 1880, sus integrantes comenzaron a vehiculizar sus afanes culturales a través de distintos canales en entre siglos diecinueve y veinte; el principal fue la prensa, pero también participaron en la gestación

13 Scavone Yegros (ed.), Brezzo (estudio preliminar), Cecilio Báez-Juan E. O'Leary. Polémica sobre la historia del Paraguay, 2012 (2008).

14 Juan E. O’Leary. Diario íntimo 1907-1920. Transcripción y edición al cuidado de Martín Romano. Bibliografía preparada por Andrea Tutte, pp. 115-116.

15 Biblioteca Nacional del Paraguay, Catálogo bibliográfico Colección Juan E. O’ Leary, Asunción, Secretaría Nacional de Cultura, 2018. El proyecto editorial fue promovido por Rubén Capdevila, y estuvo a cargo de Zayda Caballero R., y colaboraron Patricia Riveros, William Fleitas y Emilio Alarcón.

16 Para la tipología y características de la correspondencia intelectual véase Myers, "El epistolario como conversación humanista: la correspondencia intelectual de Alfonso Reyes y Genaro Estrada (1916-1939)", pp. 53-70, del mismo autor "El intelectual diplomático: Alfonso Reyes, sustantivo", pp. 82-97 y Marichal y Pita González, "Algunas reflexiones sobre la historia de los intelectuales/diplomáticos latinoamericanos en los siglos XIX y Xx", pp. 97-124. 
y edición de publicaciones que tuvieron cierta acogida en el espacio cultural paraguayo como la Revista del Instituto Paraguayo, la Revista de la Universidad Nacional, la Revista de Agronomía y de Ciencias Aplicadas.

Con excepción de los intercambios que mantuviera con el diplomático paraguayo Gregorio Benites (1834-1909), entre los años 1900-1909, los más antiguos parecen haber sido aquellos con miembros de esa generación: a partir de 1904 se conservan cartas intercambiadas con Arsenio López Decoud (19041927), Fulgencio Moreno (1912-1933), Enrique Solano López (1910-1914); desde 1920 con Manuel Domínguez (1924-1928), con Justo Pastor Benítez (1924-1935), y con letrados cercanos a esa promoción intelectual, como el caso de Juan Natalicio González (1897-1966), a quien O’Leary consideró como su dilecto discípulo y con quien mantuvo una correspondencia que, si bien con algunas interrupciones, se extendió entre los años 1920 y 1963. O’Leary buscó también, a partir de la primera década del siglo veinte, el trato epistolar con intelectuales extranjeros que pergeñaban interpretaciones históricas sobre la Guerra del Paraguay, como el uruguayo Luis Alberto de Herrera (19051954), quien publicó en 1912 La diplomacia Oriental en el Paraguay y cuyos intercambios cubren más de cincuenta años de acuerdos y desacuerdos políticos e historiográficos; también, desde 1915, con el venezolano Rufino Blanco Fombona (hasta 1939), a quien solicitó que prologase su biografía El Mariscal Solano López; desde 1926 con Carlos Pereyra (1926-1940) con motivo de la difusión del libro del mexicano titulado Francisco Solano López y la Guerra del Paraguay, y a quien invitó a redactar el prólogo de su biografía sobre el General Bernardino Caballero; con los argentinos Ernesto Quesada (1920-1926), quien publicó a inicios del siglo veinte el estudio La política argentino paraguaya, y con David Peña (1907-1928), autor de la biografía sobre Juan Facundo Quiroga; con el uruguayo José Enrique Rodó (1915) mantuvo intercambio epistolar en los años que rodearon la preparación de la obra Nuestra Epopeya y con el reconocido escritor español Miguel de Unamuno (1907-1912), a quien le hizo llegar su primer folleto sobre el conflicto titulado Historia General de la Guerra de la Triple Alianza, que publicó como capítulo de la obra colectiva Álbum Gráfico del Paraguay dada a conocer en el año 1911 en ocasión del centenario de la independencia. ${ }^{17}$ Los corresponsales se leen asiduamente, se comentan, se interpelan, se interrogan sobre la progresión de sus investigaciones, hacen circular sus textos y se esfuerzan por publicarlos en sus respectivos países. ${ }^{18}$

17 Brezzo, “Cartas prodigiosas. Juan E. O’Leary y los entresijos de la edición de sus relatos históricos sobre la Guerra del Paraguay (1919-1929)”, pp. 1-18.

18 Brezzo y Reali, Combatir con la pluma en la mano. Dos intelectuales en la Guerra del Chaco: Juan E. O'Leary y Luis Alberto de Herrera, pp. 23-123; Brezzo y Micheletti, "Libros, cartas, lecturas: La revisión de la historia en Argentina y Paraguay a través de los 
Junto a las relaciones epistolares, Juan O’Leary cultivó de forma sostenida, en el transcurso de más de cinco décadas, un diario íntimo al que definió como "las páginas de mi vida", y que registró en diecisiete cuadernos manuscritos. La primera anotación la realizó el 1 de enero de 1907, cuando tenía 28 años, la última el 24 de agosto de 1960, con 81, nueve antes de su fallecimiento. El conjunto abarca más de un millar de páginas en las que el diarista intercala apuntes personales con recortes de prensa, cartas de numerosos corresponsales, así como fotografías y tarjetas postales que figuran adheridas a sus páginas.

La Tabla 1 trata de mostrar la extensión y regularidad con que O’Leary llevó su diario:

Tabla 1

\begin{tabular}{ll}
\hline \multicolumn{1}{c}{ Diario } & Fechas \\
\hline Tomo I & Años $1907-1920$ \\
Tomo II & 14 de julio de 1936 al 26 de enero de 1937 \\
Tomo III & 29 de enero de 1937 al 24 de abril de 1937 \\
Tomo IV & 25 de mayo de 1937 al 16 de febrero de 1938 \\
Tomo V & 5 de marzo de 1938 al 16 de noviembre de 1939 \\
Tomo VI & 18 de noviembre de 1939 al 15 de mayo de 1941 \\
Tomo VII & 19 de septiembre de 1943 al 12 de junio de 1946 \\
Tomo VIII & 13 de junio de 1946 al 31 de julio de 1947 \\
Tomo IX & 11 de agosto de 1947 al 1 de marzo de 1948 \\
Tomo X & 7 de enero de 1949 al 4 de setiembre de 1949 \\
Tomo XI & 5 de octubre de 1949 al 3 de setiembre de 1950 \\
Tomo XII & 6 de septiembre de 1950 al 31 de julio de 1951 \\
Tomo XIII & 1 de agosto de 1951 al 7 de junio de 1952 \\
Tomo XIV & 9 de junio de 1952 al 7 de enero de 1954 \\
Tomo XV & 8 de enero de 1954 al 30 de febrero de 1954 \\
Tomo XVI & 2 de diciembre de 1954 al 14 de mayo de 1960 \\
Tomo XVII & 24 de agosto de 1960 \\
\hline
\end{tabular}

intercambios epistolares entre David Peña y Juan E. O'Leary”, pp. 14-30; Quinteros, “Cartas de Juan Natalicio González para o seu mestre Juan O’Leary: A autonomia literária e política do discípulo", pp. 90-114. 
A pesar de que hay dieciséis años de silencio entre los años 1920 y 1936, que pueden recapturarse, en parte, mediante la robusta correspondencia, por el volumen de la escritura y por su marco temporal, el diario de Juan O'Leary constituye un cuerpo consistente y representativo de su vida ¿Cómo podemos leerlo? ¿Para quién escribe? Una primera respuesta la podemos hallar en la intervención que realiza en el cuaderno XIII, el domingo 12 de agosto de 1951, en la que declara:

Estos apuntes, iniciados en 1936, se han prolongado hasta hoy, y seguirán, seguramente, mientras viva. Escritos rápidamente, sin preocuparme de la forma y sin hacer correcciones después, interpretan mis impresiones del momento, mi pensar y sentir ante el panorama que tengo frente a mí, mi drama íntimo, mis angustias, mis dolores... y mi fugaz felicidad. En quince años he pasado por trances amargos, he sufrido mucho, he sido feliz, a ratos. ¡Cuántos acontecimientos han desfilado ante mis ojos, en el mundo y en nuestra infortunada patria! La revolución española, la guerra mundial, los horrores del comunismo, la "guerra fría”, la de Corea, la revolución de Concepción, la vuelta al poder del Partido Colorado. Y, sobre todo, la catástrofe inmensa en nuestro hogar, la muerte de mi gran y heroica compañera. Muchas de estas páginas están escritas con lágrimas. En otras arde la pasión. Seguramente no he sido siempre justo, pero nunca he dejado de ser sincero. Y no quiero que nadie se entere de mis desahogos de hombre adolorido hasta que pasen muchos años, treinta por lo menos. Si he sido injusto, pido perdón a los agraviados sin intención por mí. Leed vosotros, hijos míos, estas páginas, en las que sentiréis palpitar mi corazón. Son para vosotros, nada más ¡Y no olvidéis al que tanto os amó!.

Sus hijos — Juan y Rosa - aparecen como los primeros destinatarios de esas páginas si bien no descarta o, en todo caso, no desaprueba, que otros lectores puedan llegar a enterarse de su contenido; es decir, parece tener en mente la eventual lectura de su diario, aunque muestra reticencias a la hora de decidirse a que otros lo lean antes de tiempo; desvela cierto disenso interior del historiador, en el sentido que no pretende poner su escritura lejos de cualesquiera. En cambio, en los apuntes compuestos entre 1907 y1920 que corresponden al primer cuaderno no aparece la posibilidad de una eventual publicidad; el diarista está escribiendo para sí mismo:

Empiezo estas anotaciones ha tiempo proyectadas el primer día de un año preñado, para mí, de incertidumbres. En estas páginas pondré toda la sinceridad de mi alma, sin ocultar mis más recónditos pensamientos. Quiero tener un confidente con quien poder desahogarme, haciéndole partícipe de mis dudas, esperanzas, ambiciones, amarguras íntimas, alegrías, y también vicios o faltas, que también tengo, a fuer de hombre. Y nadie mejor confidente que las [tachado] páginas de un libro, único capaz de guardar una muda discreción, un absoluto secreto. En este libro consignaré, al propio tiempo, todos los detalles de mi vida 
y una relación de los acontecimientos en el país o fuera de él ocurridos, que puedan interesarme. En fin, todo cuanto encuentre eco en mí dejará sus rastros en estas páginas, llamadas a ser las páginas de mi vida. ¡Cuánto lamento haber comenzado tan tarde este trabajo! Pero, en fin, isea!

Igualmente hay que observar que, en la anotación del año 1951, O’Leary ubica el origen de su diario en 1936, es decir, parece no reconocer ¿o no recordar? al primer cuaderno. El corte cronológico entre 1907 y 1960 es también particularmente interesante porque separa dos tipos de escritura. La primera, que compendia fragmentos producidos entre 1907 y 1920 puede clasificarse como un diario íntimo, según la definición de Alain Girard, en el sentido que su autor plasma en él, fundamentalmente, las vivencias de su mundo emocional, las dolencias, las frustraciones y los modos en que gestiona esas circunstancias. En cambio, el segundo escrito personal, que se extiende de 1936 a 1960, aparece más como un diario de los denominados personaldocumental, en el sentido que contiene escritos íntimos, pero también abunda el registro de hechos y sucesos externos y la reflexión sobre sí se hace menos predominante. ${ }^{19}$

\section{El DiARISTA, SU MADRE, LA GUERRA}

De los temas vinculados a la Guerra del Paraguay que circulan en los primeros cuadernos del diario quizás uno de los que ocupa mayor espacio es el laberíntico vínculo que mantuvo O’Leary con su madre, cuyos sufrimientos durante el conflicto bélico aparecen tensionados por su postura intelectual. Para dar cuenta de esto resulta de utilidad ampliar las noticias biográficas del historiador, que nació el 12 de junio de 1879 en Asunción, nueve años después que finalizaran las acciones militares de la guerra. En 1869, en Villa Occidental, territorio argentino por entonces — actual Villa Hayes - el cura vicario Tomás O' Canavery había casado al ciudadano argentino Juan O’Leary con María Dolores Urdapilleta, paraguaya, a su vez viuda de Bernardo Jovellanos, muerto sumariamente durante la guerra. El matrimonio tuvo, hasta la llegada de Juan Emiliano, tres hijos: Idalina, Andrés y Arturo.

Dolores, la madre del historiador, fue la hija menor del matrimonio formado por Pascual Urdapilleta y Cesárea Carísimo. Se había casado en primeras nupcias, como ya ha sido mencionado, con Bernardo Jovellanos Bedoya, con quien tuvo tres hijos. Para ella, la guerra fue "implacable". Luego de perder a su marido, un familiar la había denunciado a las autoridades de "derrotismo" por haber expresado, en una conversación "familiar e íntima", su impresión

19 Alain Girard, Le journal intime. Paris, Press Universitaire de France, 1993 y "El diario como género literario", pp. 31-38. 
"ante el poder del invasor en relación a los precarios recursos bélicos del país". Hallada culpable, tuvo que dejar su hogar y todo cuanto poseía para ir, como destinada ${ }^{20}$ a las cordilleras con sus tres hijos pequeños. Vino luego la derrota total del ejército paraguayo y el avance del enemigo. A medida que los aliados se aproximaban, Dolores debió internarse más y más hasta llegar a la zona de Espadín. O’Leary dedica en su diario íntimo extensos apuntes a recoger el testimonio que, asegura, había recibido de labios de su madre: según ésta aquellos fueron "días lóbregos de inmensa miseria" en los que algunas fieles criadas la acompañaban junto a tres sobrinos. Desnudos y hambrientos "no comían sino naranjas agrias y frutos silvestres de los grandes bosques". Sus dos hijitos varones perecieron de hambre, sobreviviendo sólo su hija, llamada Leopoldina. Recién en el transcurso del año 1869 pudo regresar a Asunción y conoció a Juan O'Leary, instalado con su comercio a pocos pasos de la que fuera su residencia familiar. Y se casaron enseguida. ${ }^{21}$

El padre de O'Leary era proveedor del ejército aliado y uno de los primeros en entrar a la ciudad de Asunción, siguiendo a las fuerzas de ocupación, en enero de 1869. Al momento del nacimiento del historiador era presidente de la Junta Económico-Administrativa, un órgano de gobierno municipal, y se desempeñaba también como martillero público. De comerciante "muy rico" pasó a perder toda su fortuna, acabando en la mayor pobreza. Y, antes de 1906, dejó a su familia y regresó a la Argentina donde permaneció hasta su fallecimiento en la localidad bonaerense de Pergamino, a los 84 años de edad, el 17 de agosto de 1925. La madre de O’Leary permaneció en Asunción; el hijo pasó a constituir su único sostén económico y, gracias a eso, apunta en su diario íntimo, "no conoció la miseria. Fue una gran maestra de austeridad, de orgullosa dignidad. Modeló mi alma y mi corazón. Ya muy anciana fue a vivir con mi hermana Leopoldina, en cuya casa falleció a los 93 años ¡Bendita sea una y mil veces!". ${ }^{22}$ Las sucesivas notas que el historiador dedica a su madre en la intimidad de la escritura ponen de manifiesto que los unía un lazo fuerte, complejo en relación a la guerra y que se puede rastrear aun antes de que iniciara la escritura del diario. En efecto, en 1898, habiendo superado escasamente los 18 años O'Leary publicó en un periódico asunceno un breve escrito dedicado a describir las penurias que sufriera su progenitora por orden del gobierno de Francisco Solano López, y en el que estampa un juicio lapidario:

20 Eran mujeres condenadas por algún delito político o por pertenecer a una familia sospechosa de ser opositora al gobierno. Muchas de ellas eran miembros de la élite y fueron detenidas solamente porque alguno de sus parientes masculinos estaba implicado en la conspiración real o supuesta contra el presidente o había pasado al lado aliado. Las prisioneras eran reunidas en campos en las zonas fronterizas.

21 Roma, viernes 19 de marzo de 1937. Biblioteca Nacional del Paraguay (en adelante BNP), Colección Juan E. O’Leary (en adelante CJO), Diario íntimo, Cuaderno III.

22 Ibid. 


\begin{abstract}
¡Ah, madre querida, tú me enseñaste a perdonar! Tú no guardas rencores para nadie. Pero a pesar de todo siento agigantarse el odio inmenso que llena mi alma: odio hacia el tirano y odio hacia los lobos hambrientos que se desparramaron en nuestra tierra e hicieron añicos de nuestra nacionalidad... Para tus verdugos y para los verdugos de nuestra patria, perdóname madre mía, mi odio es eterno. Tu martirio, madre, es infinito. Cada día, cada instante, se levantan ante tus ojos las sombras de tus hijos, mis hermanos, muertos de hambre en las soledades de tu peregrinación. Tú les viste morir. Tú presenciaste aquella agonía indescriptible, y después de muertos tuviste que dejar sus cuerpecitos fríos bajo una capa de tierra y una alfombra de flores ¡Pobres hermanitos míos! Yo que sé, madre, cuánto amas a esta patria desgraciada; yo que oí de tus labios la historia de todo lo que sufriste y de todo lo que sufrieron los tuyos por ella; yo que sé cuánto desprecias a los traidores, comprendo lo injusto de aquella sentencia que tú cumpliste sin protestar. Tú perdonaste al tirano, que tan brutalmente te maltrató. Yo no lo perdono. Le olvido. Y, en este día, uno mis lágrimas a las tuyas y con mi alma abrazo a esos pobres mártires, hermanitos míos, muertos de hambre en las soledades del destierro. ${ }^{23}$
\end{abstract}

A la luz de las fuertes vivencias que le produjeran los relatos maternos recogidas en estos versos - las penurias padecidas en los años de la guerra y la posterior convivencia con la pena de su madre - sería sencillo deducir que, naturalmente, O'Leary se identificaría con una visión crítica sobre el conflicto y, en particular, respecto a Francisco Solano López. Sin embargo, poco después del escrito mencionado, O’Leary publica un nuevo texto en el que se identifica con la figura de Francisco Solano López y que permite argumentar acerca de la capacidad de O'Leary de dejar atrás los vínculos afectivos y las vivencias de su progenitora sufriente. En efecto, en un artículo en el diario asunceno La Patria procura explicar, en relación al texto de 1898, que no había sido sino un "ingenuo salmo infantil" en el que hablaba el sentimiento, sin reflexión. Sostenía que ese grito de odio había sido "falso":

¿Y mi odio al tirano? No era sino una palabra. No soy yo el que hablo allí. [...] Es el ambiente el que gravita en mi alma infantil poniendo en mis palabras lo que sólo es realidad en el alma atormentada de los que necesitaban justificar su traición, de los que vinieron con el invasor, de los patricidas que le ayudaron en el degüello de cinco años. Ese odio es el odio de los vencedores que aniquilaron al Paraguay, pero no pudieron arrebatarle su gloria, que acabaron con el Héroe, pero no pudieron suprimir su grandeza. Ese odio no era mío, no era yo el que condenaba, yo que desconocía los misterios de nuestra historia y que no podía entrever la verdad en medio de la mistificación triunfante. Ese odio era un odio reflejo que venía de los que acababan de poner fuera de la ley al Mariscal López,

23 Reproducido en Doratioto, Maldita Guerra. Nueva historia de la Guerra del Paraguay, pp. 75-76. 
figurándose, arbitristas de la historia, que con un decreto se hace el juicio de la posteridad y que una ley rencorosa ha de absolverlos para siempre. Cuando escribí estas líneas aún no había despertado del todo la conciencia nacional, aún seguíamos condenándonos, repitiendo los anatemas de la Alianza... Debo decirlo con algún orgullo, aún no se habían publicado los Recuerdos de Gloria. El hombre tacha también esas y otras palabras del niño. En el tirano que abomina confunde la tiranía, vuelvo a repetirlo. El tirano que decretó el éxodo y que mató de hambre a mis hermanos en las inclementes serranías, no era un hombre. Ese hombre, enloquecido por un delirio patriótico, en medio del estrépito de las batallas, no supo siquiera del dolor de mi madre y de sus incontables penurias. El tirano no era él, era la guerra y eran los tiempos duros que se vivían. Él mismo era una víctima, sufría lo que sufría su patria, como habría de sucumbir con él. ${ }^{24}$

Y acababa el texto exculpando a López de los sufrimientos de su madre y borrando lo que había escrito:

¡Cuántos sufrieron, como mi pobre madre, crueles injusticias! Pero esas injusticias no eran la obra de un hombre, que no era sino instrumento del Destino en aquella hora apocalíptica. Borro esas líneas. Las doy por no escritas. El hombre no recibió del niño semejante herencia de odio, como el hijo no recibió de su madre sino un tesoro de amor y de benevolencia, de firme patriotismo y de gratitud imperecedera para todos los que, víctimas de errores o de injusticias, perecieron, leales, a la sombra $\mathrm{d}^{25} \mathrm{e}$ nuestra bandera tricolor. Sólo así he podido hacer una campaña histórica objetiva, proclamando la verdad, poniéndome por encima de sentimientos avasalladores que pudieron nublar mi juicio cuando aún no había abandonado del todo la adolescencia pero que fueron depuestos más tarde, cuando abracé resueltamente el patriótico apostolado a que he consagrado mi existencia. Después de leer ese canto en prosa al dolor de los míos se podrá juzgar de la imparcialidad de mi propaganda.

Si se cotejan estos dos escritos de O'Leary con los apuntes íntimos sobre su madre, es posible recuperar una serie de atributos: la muestra siempre como "una heroína" y una mujer ejemplar; la describe como "una gran dama. Toda una señora", de una estirpe que ya no existía en el Paraguay, "prudente, educada, fina, de modales distinguidos, hermosa hasta en su extrema ancianidad". El diarista recrea sus vivencias y sentimientos en cada aniversario del fallecimiento de la madre en apuntes como el que sigue:

Todo el día de hoy he recordado a mi pobre madre. Hoy es el aniversario de su fallecimiento. Heroína, digna de respeto y admiración. Madre ejemplar ¡Mujer incomparable! La llevo viva en mi corazón. Su bondad ilumina mi vida. Su

24 “A mi madre", La Patria, Asunción, 28 de enero de 1918.

25 Ibid. 
recuerdo es parte de mi existencia. Mi gran dolor — sin consuelo- es no haber podido hacerla feliz como se merecía. Murió antes de que me redimiera de la miseria... Pero creo haberle brindado no pocas satisfacciones. Y, sobre todo, no haberle causado jamás el menor pesar. Fui un hijo modelo dentro de mis medios. E hice honor a su sangre y a su raza... ${ }^{26}$

La fisonomía del lazo materno-filial resumida hasta aquí conduce a la problematización en torno a las motivaciones que llevaron a O'Leary a empeñarse, cumplidos sus veinte años, en una infatigable campaña intelectual de reivindicación del Mariscal Francisco Solano López - causante de las penurias de su madre - y de su actuación durante la guerra; es decir ¿cómo explicar su transformación de crítico a panegirista de Solano López? El historiador brasileño Francisco F. Doratioto sostiene, sobre la base de informes diplomáticos, que esa conversión se debió propiamente a motivos económicos. Explica que luego de la muerte de Francisco Solano López y finalizada la guerra, los bienes de la familia presidencial fueron transferidos al estado paraguayo. A comienzos del siglo veinte, Enrique Solano López, hijo del ex presidente de Paraguay y de Elisa Lynch inició una demanda para que se les devolviesen dichos bienes (tierras y casas) a los que, sostenía, eran los legítimos herederos, es decir, los hijos que sobrevivieron al conflicto. De acuerdo a las fuentes estudiadas por Doratioto, los herederos de Solano López, interesados en recuperar sus bienes, se pusieron de acuerdo con paraguayos influyentes con miras a lograr la revocación del decreto de 1869 [que había declarado a Solano López traidor a la patria y por el que se le confiscaran todas sus posesiones] y recobrar sus derechos civiles; de modo que "el señor O'Leary se puso a defender los intereses lopistas inconfesables de dinero" y se mantuvo en ello al darse cuenta que podría obtener prestigio y sacar provecho material. ${ }^{27}$

Claro está que este argumento, a la luz de los apuntes íntimos, parece no alcanzar para explicar la mutación interpretativa. Más recientemente, en el estudio que Luc Capdevila dedica a analizar el influjo del discurso histórico de O'Leary en la sociedad paraguaya le atribuye una serie de mecanismos por los cuales al mismo tiempo de construir su interpretación sobre la guerra edifica su propia identidad. Sostiene que la concentración de la memoria sobre el "acontecimiento monstruoso" de la guerra en la personalidad del Mariscal López, por parte del historiador, encontró un eco en la memoria colectiva paraguaya porque de ese modo la sociedad del país vencido pudo dar sentido "épico" a la tragedia incomprensible e indecible que acechaba a la mayoría; en este contexto, O’Leary hizo de la rehabilitación del Mariscal una "victoria 
personal", construyendo su propia "leyenda" y, puede agregarse, su propia identidad personal. ${ }^{28}$

La escritora Jennifer French se arriesga a sostener, sobre la base del psicoanálisis, la necesidad de replantear la conversión de O’Leary y de situarla como efecto del traumatismo que le supuso la guerra, como un acontecimiento repentino y abrumador. Siguiendo esta línea, el trauma materno que definió la realidad psíquica de O’Leary condicionó su cambio intelectual.

Si la poesía dedicada a su madre [en 1898], era una muestra de devoción filial y fraterna, revela también algunas pistas de la transformación inminente del escritor: el distanciamiento con su madre, a quien percibe ensimismada en su pasado trágico, el deseo un poco desesperado de ganar su atención y afecto, la idealización un poco ambivalente de los hermanos muertos, el dolor que siente por ellos y el deseo de enterrarlos para siempre, de completar de una vez el duelo que la madre sola no puede realizar". En fin, French concluye que la conversión de O'Leary del odio a la exaltación de López se debió al rechazo de un peso imposible de soportar — las condiciones de la posguerra- y de deberes — ser el sostén económico y la contención afectiva de su madre- que ni buscó ni quería. $^{29}$

Se podría aducir que los argumentos de Capdevila y de French se sitúan más o menos cerca del terreno especulativo antes que en pruebas empíricas; sin embargo, los apuntes íntimos parecen reforzar tales posicionamientos. A los efectos de sumar otro elemento de análisis, aunque tangencial, hay que decir que la correspondencia privada entre O'Leary y su padre muestra que la relación paterno-filial discurrió por carriles muy diferentes. En lo que hace al intercambio epistolar fechado entre Buenos Aires y Asunción en las dos primeras décadas del siglo veinte, no ha sido posible hallar referencias a recuerdos o vivencias vinculadas a la guerra con excepción, quizás, de alguna mención indirecta, como la contenida en la carta del 6 de abril de 1910 en la que el padre de O’Leary escribe: “Recibí por Ayala la carta que me mandaste por lo que veo que recibiste Mis Recuerdos; pronto, creo, si la salud de mi joven amanuense se encuentra bien, escribiré mis recuerdos de la toma de Asunción y el saqueo por los marinos brasileros y otros que te han de causar bastante sorpresa cuando los leas" ${ }^{30}$ Por el contrario, las misivas se limitan, en general, a temas vinculados a diligencias prácticas: el padre solicita el envío de periódicos y de cigarros, en tanto el hijo le encomienda la compra de géneros

28 Capdevila, Une guerre totale: Paraguay, 1864 - 1870, pp. 69-117 y 491-497.

29 French, "El peso de tanta pena: la Guerra de la Triple Alianza como trauma intergeneracional", pp. 317-339.

30 Buenos Aires, 6 de abril de 1910, BNP, CJO, Correspondencia pública y privada, carpeta XXXI. 
y prendas de vestir para su esposa e hijos. Un detalle llamativo, por ejemplo, es la ausencia de menciones y referencias, por parte del padre, hacia la que seguía siendo su esposa, tal como lo demuestran los saludos finales de las cartas, entre cuyos recuerdos afectuosos enumera, sin excepción, a Dorila (la esposa de O'Leary) a Leopoldina (su hija), a los hijos de ésta y de O'Leary (sus nietos), pero, en ningún caso referencia alguna a Dolores. Tan sólo en un breve apunte en su diario íntimo, O'Leary reconoce a su padre el mérito de haber sido "testigo del épico martirio del Paraguay y obrero de su resurgimiento, que me enseñó a amar a su gloriosa tierra argentina y encendió en mi corazón el fuego del más puro patriotismo". Y, años después de su fallecimiento, lo caracteriza como portador de una "noble fisonomía y la nobleza de su raza". "Me conmueve", escribe O'Leary en su diario personal en momentos en que miraba un antiguo retrato de su padre, "es el hombre joven todavía, lleno de vida, arrogante y fuerte. ¡Una evocación de mi primera juventud! ¡Parece que lo veo en aquellos ya lejanos tiempos!". ${ }^{31}$

El epistolario padre-hijo, así como las escasas referencias en el diario íntimo parecen demostrar que el progenitor de O'Leary tuvo, en efecto, una influencia menos compleja que la de su madre en su itinerario intelectual y espiritual.

Ahora bien, si se retoma el diario íntimo de O'Leary en la búsqueda de los orígenes de su operación de rehabilitación histórica del Mariscal Francisco Solano López es posible sumar nuevos datos de cara a la explicación de su mutación interpretativa.

\section{El diarista y la ReHabilitación de Francisco Solano López}

Como ya se ha hecho notar es habitual que O’Leary intercale en las páginas de su diario íntimo, fotografías, postales y cartas de amigos y conocidos. Se muestra especialmente activo en dejar ese tipo de constancias entre los años 1907 y 1908. Así, en el mes de enero de 1907 da cuenta del inicio de una relación epistolar con el historiador argentino David Peña (1862-1930) con motivo de leer su biografía de Juan Facundo Quiroga que había sido editada unos meses antes en Buenos Aires. El libro, que O’Leary compró en la librería asunceña de Jordán y Villamil “a 30 pesos” según apunta en el diario, compilaba quince conferencias que David Peña dictara en Facultad de Filosofía y Letras de la Universidad de Buenos Aires, muy resonantes por la defensa que en ellas realizara de Quiroga, a contrapelo de la obra de Domingo F. Sarmiento. Debido al interés que habían despertado, su autor decidió convertirlas al formato de libro con el fin de darles una mayor difusión y alcanzar un público más amplio 
que el de los claustros universitarios, atraído por los rumores de que su tesis entraba en abierta polémica con la versión canónica que la historiografía liberal había consagrado sobre los denominados "caudillos". Para ello, Peña revisó los manuscritos, les realizó algunas modificaciones y agregados y los entregó a la Casa de Coni Hermanos para su impresión y comercialización. ${ }^{32}$

Pues bien, luego de leer la biografía del caudillo argentino, O'Leary produce una anotación extensa en su diario que permite calibrar el impacto que le produjo:

Hermoso libro. Su lectura me ha dejado una grata impresión. Quiroga resulta un prócer argentino. Desvanecida la sangrienta leyenda forjada por Sarmiento queda la vida del grande hombre, reducida a sus justas proporciones. Facundo ya no es el bárbaro, sediento de sangre, corrompido, enemigo jurado de la civilización como lo pintó el asesino de Peñaloza, el "doctor de Michigan". Queda, como dice Peña, el general Juan Facundo Quiroga, representante nato de las provincias y precursor de Urquiza en la obra de la organización nacional. La teoría de Peña se puede fácilmente aplicar al Mariscal López. Un libro así de reivindicación es mi más constante preocupación. Alguna vez lo haré. Francamente me seducen los hombres que, como David Peña, defienden a los perseguidos, a quienes se ceba el odio inconsciente de las multitudes. David Peña ha vindicado a Alberdi levantándole un monumento en Buenos Aires. Y ahora vindica a Quiroga. Los dos hombres más odiados de su país. Tiene que ser un alma fuerte. Y son pocos en la Argentina: Saldías y él. Y si Rosas y Quiroga tienen sus panegiristas ¿No podrá tenerlos el Mariscal López? López no cometió ni la millonésima parte de los crímenes de Rosas, ni anarquizó a su patria como Quiroga. Loco por el desastre, traicionado, vendido, cometió actos de crueldad que condeno, pero que son perfectamente explicables. Derramó sangre paraguaya, pero en defensa de la patria por cuya causa pereció en el último campo de batalla. Es mil veces más grande que Rosas y Quiroga juntos. Con razón dijo Alberdi que no tenía un igual en la América. ${ }^{33}$

$\mathrm{Y}$, a continuación, transcribe una carta que le remitiera al historiador argentino en la misma fecha en la que anotó sus impresiones. Luego de presentarse. le manifiesta la identificación con sus ideas, con el espíritu que, según entendía, había inspirado el estudio sobre el caudillo argentino:

32 Brezzo y Micheletti, "Libros, cartas, lecturas: la revisión de la historia en Argentina y Paraguay a través de los intercambios epistolares entre David Peña y Juan E. O'Leary", pp. 14-30; Micheletti, "Facundo Quiroga rehabilitado". Una aproximación al contexto de producción, repercusiones y aportes historiográficos del libro de David Peña (1906)”, pp. 125-153.

33 San Lorenzo (Paraguay), 3 de enero de 1907, BNP, CJO, diario íntimo, Cuaderno I. 
Años hace que me consagro a una obra semejante desde las columnas de la prensa de mi país. No le asombre, pues, mi actitud, que ella es hija del entusiasmo que no puede menos que producirme esta afinidad entre su pensamiento y el mío. Cuan pocos son los hombres que, como usted, se atreven a desafiar los prejuicios en nombre de la justicia histórica. Yo que he combatido por todas partes en mi país brego en defensa de las glorias de mi patria, aprecio en su justo valor su actitud. Yo se las luchas, los trabajos, las amarguras que importa este noble apostolado. Créame, pues, su admirador y cuénteme en el número de los que le acompañan en su cruzada de vindicación iniciada con el monumento al más grande argentino -Alberdi-y meritoriamente continuada en su último libro. ${ }^{34}$

Se trasunta la admiración de O'Leary hacia el autor en cuyas ideas puede filiar su propia posición historiográfica. Se refleja, asimismo, el claro sentido de exaltación patriótica que le confiere a su labor como historiador, y la operación que promete poner en marcha para trasformar a López en héroe máximo y mártir sacrificado de su nación. Estas anotaciones son relevantes en varios sentidos. Uno es que permite precisar el extenso período de gestación de la biografía de Francisco Solano López que O’Leary publicara en 1920. Otro sentido notable es que tanto los apuntes íntimos como la carta que remite a David Peña parecen funcionar como ante texto o como texto-embrión en los que adelanta sus ideas y argumentos que años después recogerá en la obra impresa. En efecto, O’Leary publica El Mariscal López en 1920, un libro cuya tirada de 2000 ejemplares se vendió, según su testimonio, "en dos semanas sin que hubiera tiempo de difundirla fuera de la capital". De modo que poco después inició la preparación de una segunda edición e invitó al escritor venezolano Rufino Blanco Fombona para que redactase el prólogo. ${ }^{35}$ El propósito principal de la biografía era reivindicar la actuación de Francisco Solano López durante la guerra y demostrar la injusticia de los atributos de bárbaro, déspota y sanguinario con los que era caracterizado en lecturas sobre el conflicto que circulaban en el espacio platense. ${ }^{36}$

La función del apunte íntimo como ante texto demuestra, a su vez, cómo los ámbitos de lo público y lo privado no son compartimientos que se excluyen, al estar integrados en un proyecto historiográfico que aprovecha la meditación íntima con vistas a producir el texto público.

$34 \quad$ Ibid

35 De Rufino Blanco Fombona a Juan E. O’Leary, Madrid, 21 de julio de 1921, BNP, CJO, Correspondencia oficial y privada, carpeta XXXVI.

36 Baratta, "La Guerra del Paraguay y la historiografía argentina”, pp. 98-115; Reali, "Los intercambios epistolares entre Luis A. de Herrera y Juan E. O’Leary en el período de surgimiento y consolidación de un movimiento historiográfico revisionista sobre la Guerra del Paraguay", pp. 391-411. 
En los años que siguieron a la publicación de la biografía, la rehabilitación histórica del Mariscal Francisco Solano López ocupó el lugar central en la operación historiográfica de O'Leary, que tendrá su corolario cuando los restos mortales de López serán trasladados desde Cerro Corá, sitio en el que fue abatido por fuerzas brasileñas el $1^{\circ}$ de marzo de 1870 y que marcó el final de la guerra, hasta el monumento denominado Panteón Nacional de los Héroes, en Asunción. El diario íntimo de O'Leary nos acerca la extensa anotación que produjo el 12 de octubre de 1936 en ocasión de los actos que rodearon el traslado. Desde París, ciudad en la que residía temporalmente en tanto aguadaba asumir funciones diplomáticas, transporta su imaginación sobre lo acontecido en la capital paraguaya y pone por escrito sus sentimientos. Se trata de una cita larga, pero sin desperdicio:

¡Coronamiento de mi obra! Pero es muy posible que no me hayan recordado siquiera. ¡No importa! No soy yo el triunfante, es mi ideal. Yo puedo ser olvidado, por ahora, pero eso queda. $Y$ es lección para esa misma juventud envenenada de comunismo, podrida de pies a cabeza, que pretende desconocerme. Ella, estéril como tierra salitrera, está en presencia de la obra de un hombre, que en treinta y seis años de lucha y sacrificio reforzó el alma nacional, devolvió la dignidad y el orgullo a su pueblo vencido, le dio esperanza, le inyectó optimismo y lo hizo andar de nuevo por el camino del heroísmo, para ser el heredero y continuador de una gloriosa tradición. Los que hablan de "imperialismos" no saben que yo rompí esa coyunda, la del imperialismo argentino-brasileño, imperialismo político que hacía del Paraguay una factoría. Contra esa ignominia luché solo. López fue mi bandera, porque López representa nuestra soberanía atropellada y la resolución de ser paraguayos solamente. Podrán olvidarme, pero ahí están mis obras y ahí está mi propaganda que llena, desde 1900, la prensa nacional. Y ahí está el mariscal López vindicado oficialmente, traído de Cerro Corá y colocado como perenne llama de patriotismo en el corazón de la capital de su patria. Queda allí mi obra y mi doctrina. ¡Y nadie me sacará lo que es mío! ${ }^{37}$

O'Leary recupera en este apunte la labor que principiara en los primeros compases del siglo veinte en la construcción de una interpretación de la guerra y del principal actor paraguayo, y celebra en París lo que considera un triunfo personal, una victoria colosal, un premio merecido a sus sacrificios. En el escrito aparece con nitidez la construcción que hace, al mismo tiempo, de un discurso histórico sobre la guerra y de sí mismo; esto es, en el apunte modela su imagen pública y marca el lugar que él piensa que merece en la vida política y cultural del Paraguay. Es en ese sentido que quizás quepa aplicar a su personalidad el principio de sinceridad inversa en lo que se refiere a la comprensión de sí mismo que construye el autor, es decir, narra de tal manera

37 París, 12 de octubre de 1936, BNP-CJO, Diario íntimo, Cuaderno II. 
los hechos que el retrato de sí que constituye su vida es idéntico al retrato ideal que desea; dicho más sencillamente: que sea tal como quiere ser. ${ }^{38}$ De modo que lo público y lo privado aparecen, una vez más, soldados en la escritura íntima en una simbiosis que le hace exclamar "yo soy el Paraguay" y no duda que su discurso se convertirá en "unánime" — hegemónico — en los años siguientes. Esta certeza se replica en otras partes del manuscrito privado en los que la identidad del diarista se resume en expresiones como "¡Soy el único autor de la glorificación del Mariscal de Hierro!". ${ }^{39}$

\section{El diarista y la “heroína del Paraguay”}

Una tercera marca en el diario de O’Leary en relación a la guerra refiere a los apuntes que dedica a Elisa Alicia Lynch (1833-1886), la compañera de Francisco Solano López y madre de sus seis hijos. Hay que recordar que desde el final del conflicto, paraguayos y extranjeros tejieron variopintos relatos en torno a ella hasta convertirla en un enigma de la historia paraguaya. A veces aparecía como el motor de acciones abominables o nobles y en otras "como simple figurante del caótico fresco de una sociedad en camino hacia su destrucción." ${ }^{40}$ En 1854, el hijo del entonces presidente del Paraguay, Carlos Antonio López, encabezó la primera misión diplomática del Paraguay en Europa, en cuyo transcurso conoció a Elisa Lynch en París. Se enamoró de ella y le pidió que fuera su acompañante en el resto del viaje. Al finalizar las gestiones diplomáticas, Lynch estaba embarazada. En 1855 se reunió con Solano López en Asunción. Nunca se casaron. La familia de López se opuso a esa unión de hecho con una extranjera sobre quien pesaba, además, la supuesta condición de "cortesana parisina". Las costumbres, las modas y el estilo de vida que introdujo Elisa Lynch también suscitaron controversias en la conservadora sociedad paraguaya. Durante todo el conflicto contra la Triple Alianza, Elisa no se separó de Solano López y fue testigo de su muerte en Cerro Corá el 1 de marzo de 1870. La propaganda de guerra contribuyó, por su parte, a abonar el vilipendio de la mujer, a quien se acusaba de seducir al heredero del gobierno del Paraguay, convirtiéndolo en un dictador sanguinario. Las circunstancias políticas derivadas de la finalización de las acciones militares y la condena oficial que pesó sobre López determinaron que Elisa Lynch abandonara el Paraguay y se refugiara en París donde vivió sus últimos años, en tanto

Girard, pp. 31-38.

París, miércoles 9 de diciembre de 1936, BNP, CJO, Diario íntimo, Cuaderno II.

Dionisi, "Novelando se escribe la historia. De lo dramático a lo espectacular", pp. 207-229 y

"Lecturas y re lecturas de la "Madama del Paraguay". Un recorrido bibliográfico", pp. 365377. 
presenciaba cómo se destruía su reputación con relatos en los que se le tildaba de prostituta, tirana y torturadora. ${ }^{41}$

Las referencias sobre Elisa Lynch en el diario íntimo de O'Leary inician durante su estancia en Europa como representante diplomático del Paraguay ante los gobiernos de España y de Italia entre los años 1936 y 1938. Para entonces era ya uno de los actores político- culturales más influyentes de su país. Integraba la comisión directiva de la Asociación Nacional Republicana o partido Colorado, había sido director del Archivo Nacional del Paraguay y, durante la guerra del Chaco contra Bolivia (1932-1935), había llevado a cabo una campaña periodística robusta tendiente a legitimar la causa paraguaya.

El primer apunte que figura en el diario corresponde a una visita que realiza O'Leary con su familia a la tumba de Elisa Alicia Lynch en el cementerio de Père Lachaise en París el domingo 13 de septiembre en horas de la tarde. El diarista redacta un extenso escrito en el que vuelca sus observaciones e impresiones en torno a la que califica, sin dubitativos, como una "mujer extraordinaria". En primer término, ofrece una descripción del monumento:

Es modesto pero bello. Es todo de piedra, rodeado de cadenas, con pilares de bronce. En el frente, el escudo de los López. En el costado de la derecha, el escudo paraguayo, con la estrella en el centro. En el otro costado, el otro escudo, con el león y el gorro frigio. ${ }^{42}$

Transcribe, luego, el epitafio: "erigido por Enrique, Federico y Carlos Solano López en 1886 a la ilustre memoria de su siempre querida e inolvidable madre, señora doña Alicia Lynch López, muerta el 25 de julio de 1886". A continuación, sinteriza sus sentimientos de este modo: "¡Ante su tumba sentí, en toda su intensidad, la tragedia de su vida! ¿Qué dolor el suyo! Regresar de Cerro Corá para ser escarnecida por las que llegaron con el invasor, con las que celebraban con bailes y festines, con los aliados, la catástrofe final". Desenvuelve, a continuación, unas reflexiones para fundamentar el lugar que, según entiende, le corresponde ocupar a Elisa Lynch en el relato sobre la guerra: la necesidad de hacerle justicia y de "hacer caer en pedazos" la leyenda infame que pesa sobre su memoria. El historiador escribe que siente el deber de reconstruir la reputación de la compañera del Mariscal, destruida con relatos en los que se le tilda de prostituta, tirana y torturadora. Cabe mencionar aquí que, al momento de la visita de O'Leary a la tumba en Père Lachaise, no se habían publicado propiamente obras históricas sobre la compañera de Solano López. El argentino Héctor Florencio Varela había editado en Buenos Aires, en 1870,

Ibid.

42 París, 13 de septiembre de 1936 y París, 2 de noviembre de 1936. BNP, CJO, diario íntimo, Cuaderno II. 
un texto titulado Elisa Lynch, en la que, en efecto, la criticaba con dureza. Se trató, bien se conoce, de una biografía preparada en interlocución con la historiografía liberal sobre la guerra, que ayudó a solidificar la interpretación crítica sobre la compañera de López. ${ }^{43} \mathrm{El}$ año anterior al apunte producido por O’Leary, es decir, en1935, vio la luz de la imprenta, en Londres, la novela Land of woman. The Tale of a lost nation, de la escritora alemana Katharina von Dowbrowski. Esto era todo lo que se había publicado. En esta línea, los apuntes íntimos del historiador paraguayo permitirían filiar su operación político historiográfica de rehabilitación que en los años siguientes convertiría a Elisa Lynch en la "heroína del Paraguay". Como botón de muestra de esto último cabe mencionar que tres años después de su anotación íntima, en decir, en 1939, cuando el escritor paraguayo Héctor Francisco Decoud publicaría la biografía titulada Elisa Lynch de Quatrefages subrayara que el principal objetivo de la obra consistirá en "reprimir la interpretación del nacionalismo lopista sobre la compañera de López":

Hace mucho tiempo que mis amigos me piden que escriba una Biografía de la célebre concubina del tirano de Paraguay, Mariscal Francisco Solano López. Siempre me negué a hacer eso, en homenaje a la sociedad de mi patria... Más ahora, ante la tentativa de elevarla por encima de los millares de muertos que ella dejó en su camino...levanto mi vos de protesta por semejante insulto a la Patria y llamo la atención del Pueblo Paraguayo en relación a los intereses ocultos que se esconden tras esa osadía. ${ }^{44}$

Lo que O'Leary escribe en la intimidad en 1936 tendrá su corolario en 1961 cuando el gobierno paraguayo de Alfredo Stroessner (1954-1989) recibirá, en el puerto de Asunción, a los restos mortales de Elisa Lynch traídos desde Francia como parte de un proyecto que pergeñó O'Leary y que se inscribió en la propaganda ideológica impuesta por el régimen político paraguayo. La repatriación estuvo precedida por la publicación de una biografía titulada Madama Lynch, escrita por el autor francés residente en Paraguay, Henri Pitaud (1899-1991), y que contó con un prólogo escrito por O'Leary en el que declaraba que, finalmente, “después de estudiarla a la luz de una crítica desapasionada, extrayendo la verdad del cúmulo de falsedades con las que se pretendía desfigurarla, Henri Pitaud compuso una obra que hace justicia a una mujer admirable [la misma expresión que utilizara en su diario en 1936], injuriada por panfletistas miserables". ${ }^{45}$

$43 \quad$ Neres Silva, "As imagens do jornalista Héctor Florencio Varela sobre Madame Lynch e o Paraguai no pós-Guerra da Tríplice Aliança”, pp. 44-71.

44 Ibid.

45 Henri Pitaud, Madama Lynch, Asunción, Sociedad de Estudio y Empresa Franco-paraguaya, 1958, pp. 9-12. El prólogo de O’Leary está fechado en Asunción, el 12 de abril de 1956. 
Entre los apuntes de 1936 y la apoteosis de 1961, la escritura íntima permite restituir la operación político historiográfica en torno a Elisa Lynch que le demandó a O'Leary casi treinta años, casi tantos como los que necesitó para la rehabilitación de Francisco Solano López.

\section{CONSIDERACIONES FINALES}

Se puede argüir, con razón, que el diario íntimo presenta sólo una visión parcial de una vida y de un ser humano, que es una misma luz la que ilumina las interioridades, por lo que habrá que suponer una serie de zonas vedadas que, de aclararse, podrían equilibrar las sombras que se nos dan. Es cierto que entrar en la cuestión de la verdad en relación al estudio de un diario íntimo es un complicado problema. Sin embargo, en el plano de la sinceridad, no habría por qué cuestionar que lo que escribe O'Leary en su diario en relación a la guerra y a algunos de sus actores principales posee la cualidad de la sinceridad, aunque ello no sea necesariamente la verdad. Y por ello, su escritura resulta no únicamente de utilidad como fuente para reconstruir su subjetividad, sino que también aporta elementos relevantes para examinar la construcción de su discurso histórico, su visión sobre el pasado paraguayo en el que el conflicto bélico ocupó un lugar principal.

En cuanto a la relación de Juan O'Leary con su madre y el giro interpretativo sobre la guerra, el estudio del manuscrito íntimo ofrece pistas para profundizar en el vínculo materno-filial, la experiencia de la guerra y las secuelas psíquicas y aporta datos para problematizar, aunque sin resolverlo de momento, su conversión interpretativa sobre el conflicto bélico. No obstante, los apuntes producidos por O'Leary en 1907, así como el intercambio con el historiador David Peña, permiten filiar el giro interpretativo de O'Leary respecto al Marisca Francisco Solano López. Esta verificación ratifica la necesidad de conectar, en este tipo de estudios, la trayectoria personal y la profesional, y profundizar de qué modo las experiencias íntimas condicionan la producción intelectual.

En los casos de las anotaciones en torno a Alicia Elisa Lynch y Francisco Solano López, los distintos formatos de la escritura privada - epistolario y diario íntimo- permiten precisar el extenso período de gestación de la biografía sobre el Mariscal López, así como la operación político historiográfica de rehabilitación de Alicia Lynch que inició O’Leary en 1936, tras la visita a su tumba en el cementerio parisino.

Finalmente, los resultados del entrecruzamiento de la escritura íntima y la obra histórica de O'Leary sobre la Guerra del Paraguay contribuyen a ensanchar el conocimiento acerca de los orígenes del denominado revisionismo paraguayo y conectarlo con las tempranas expresiones revisionistas en la región 
del Río de la Plata, como son los casos representativos de la correspondencia que O’Leary mantuvo con el argentino David Peña y el epistolario del uruguayo Luis Alberto de Herrera.

\section{FueNTES DOCUMENTALES}

Biblioteca Nacional del Paraguay, Colección Documental Juan Emiliano O’Leary, Serie Correspondencia Pública y Privada, y Diario íntimo.

Biblioteca Nacional del Paraguay, Catálogo bibliográfico de la Colección Juan E. O’Leary, Asunción, Secretaría Nacional de Cultura, 2018.

\section{REFERENCIAS}

Aurell, Jaume, "Textos autobiográficos como fontes historiográficas: relendo a Fernand Braudel e Anne Kriegel”, História, vol. 33, 2014, pp. 340-364.

DOI: https://doi.org/10.1590/S0101-90742014000100016

Aurell, Jaume, "Del logocentrismo a la textualidad: la autobiografía académica como intervención historiográfica", Edad Media. Revista de Historia, núm. 9, 2008, pp. 192-222.

Aurell, Jaume (ed.), La historia de España en primera persona. Autobiografías de historiadores hispanistas, Madrid, Base, 2013.

Baratta, "La Guerra del Paraguay y la historiografía argentina", Historia da historiografía, núm. 14, 2014, pp. 98-115.

DOI: https://doi.org/10.15848/hh.v0i14.614

Batticuore, Graciela, "La vida en las cartas: Ricardo Palma entre escritoras", Revista Landa, vol. 6, núm. 2, 2018, pp. 161-176.

Bouvet, Nora, La cultura epistolar, Buenos Aires, Eudeba, 2006.

Brezzo, Liliana, “Cartas prodigiosas. Juan E. O’Leary y los entresijos de la edición de sus relatos históricos sobre la Guerra del Paraguay (1919-1929)", Revista Páginas, núm. 11, 2019, pp. 1-18. DOI: https://doi.org/10.35305/rp.v11i25.328

Brezzo, Liliana y Reali, María Laura, Combatir con la pluma en la mano. Dos intelectuales en la Guerra del Chaco: Juan E. O'Leary y Luis Alberto de Herrera. Asunción, Servilibro, 2017.

Brezzo, Liliana y Micheletti, María Gabriela, "Libros, cartas, lecturas: la revisión de la historia en Argentina y Paraguay a través de los intercambios epistolares entre David Peña y Juan E. O'Leary", História da Historiografia, núm. 20, 2016. pp. 14-30. DOI: https://doi.org/10.15848/hh.v0i20.981

Brezzo, Liliana, "El historiador y el general: imposiciones y disensos en torno a la interpretación pública de la historia en Paraguay", Nuevo Mundo Mundos Nuevos [En ligne], Questions du temps présent, mis en ligne le 03 décembre 2014, DOI: https://doi.org/10.4000/nuevomundo.67479

Caballé, Anna, Narcisos de tinta. Ensayos sobre la autobiografía en lengua castellana. Siglos XIX Y XX, Málaga, 1995. 
Capdevila, Luc, Una guerre totale. Paraguay, 1864-1870, Rennes, Press Universitaires de Rennes, 2007. DOI: https://doi.org/10.4000/books.pur.17177

Costa Motta, Romilda y de Souza Fredrigo, Fabiana (coords.), "Escritas de sí nas Américas", Revista Eletrônica da ANPHLAC, 2018, pp. 1-9.

DOI: https://doi.org/10.46752/anphlac.24.2018.3075

Dionisi, María Gabriela, "Novelando se escribe la historia. De lo dramático a lo espectacular", Paraguay en la historia, la literatura y la memoria, Asunción, Tiempo de Historia, 2011, pp. 207-229.

_, "Lecturas y re lecturas de la "Madama del Paraguay". Un recorrido bibliográfico", Les guerres du Paraguay aux XIX et XX siècles, Paris, CoLibris, 2007, pp. 365-377.

Doratioto, Francisco, Maldita guerra. Nueva historia de la Guerra del Paraguay, Buenos Aires, EMECÉ, 2004.

Doratioto, "El nacionalismo lopizta paraguayo", América sin nombre, núm. 4, 2002, pp. 18-22. DOI: https://doi.org/10.14198/AMESN2002.4.04

French, "El peso de tanta pena: la Guerra de la Triple Alianza como trauma intergeneracional”, Juan Manuel Casal y Thomas Whigham (comp.), Paraguay en la historia, la literatura y la memoria, Asunción, Tiempo de Historia, 2012, pp. 317-339.

Girard, Alan, Le journal intime, Paris, 1993.

Halperin Donghi, Tulio, Son memorias, Buenos Aires, Siglo XXI, 2008.

Hierro, Manuel, "La comunicación callada de la literatura: reflexión teórica sobre el diario íntimo", Mediatika, núm. 7, 1999, pp. 103-127.

Marichal, Carlos; Pita González, Alexandra, "Algunas reflexiones sobre la historia de los intelectuales/diplomáticos latinoamericanos en los siglos XIX y Xx", Revista Historia de América, núm. 156, 2019, pp. 97-124.

DOI: https://doi.org/10.35424/rha.156.2019.235

Micheletti, María Gabriela, "Facundo Quiroga rehabilitado". Una aproximación al contexto de producción, repercusiones y aportes historiográficos del libro de David Peña (1906)", Boletín del Instituto de Historia Argentina y Americana "Dr. Emilio Ravignani”, núm. 42, 2015, pp. 125-153.

Myers, Jorge, "El epistolario como conversación humanista: la correspondencia intelectual de Alfonso Reyes y Genaro Estrada (1916-1939)", Políticas de la Memoria, núm. 15, 2014-2015, pp. 53-70.

Myers, Jorge, "El intelectual diplomático: Alfonso Reyes, sustantivo", Carlos Altamirano (org.), Historia de los Intelectuales en América Latina: Los avatares de la "ciudad letrada" en el siglo $\mathrm{XX}$, tomo 2, Buenos Aires, Katz, 2010, tomo 2, pp. 82-97.

Neres Silva, "As imagens do jornalista Héctor Florencio Varela sobre Madame Lynch e o Paraguai no pós-Guerra da Tríplice Aliança", Revista Electrónica da ANPHLAC, no. 24, 2018, pp. 44-71.

DOI: https://doi.org/10.46752/anphlac.24.2018.2949

O’Leary, Juan E., Recuerdos de Gloria, (comp.) Sebastián Scavone Yegros, Edición al cuidado de Ricardo Scavone Yegros, Asunción, Servilibro, 2008. 
O’Leary, Juan E., Diario intimo. 1907-1920, Edición a cargo de Martín Romano, Asunción, Tiempo de Historia, 2018.

Peiró Ignacio, “La contemplación de Narciso: la 'vocación autobiográfica' de los historiadores”, Miguel Ángel Ruiz Carnicer y Carmen Frías Corredor, Nuevas tendencias historiográficas e historia local en España, Huesca, Instituto de Estudios Altoaragoneses, 2001, pp. 361-388.

Peluffo, Ana y Maíz, Claudio, “Afectos, redes y epistolarios”, Revista Landa, vol. 6, núm. 2, 2018, pp. 132-139.

Polémica sobre la Historia del Paraguay. Compilación y edición de los textos de Ricardo Scavone Yegros y Sebastián Scavone Yegros. Estudio preliminar de Liliana M. Brezzo, Asunción, Tiempo de Historia, (2008) 2012.

Quinteros, Marcela Cristina, "Cartas de Juan Natalicio González para o seu mestre Juan O'Leary: A autonomia literária e política do discípulo", Revista Ambivalências, núm. 3, 2016, pp. 90-114.

DOI: https://doi.org/10.21665/2318-3888.v3n6p90-114

Reali, María Laura, "Los intercambios epistolares entre Luis A. de Herrera y Juan E. O'Leary en el período de surgimiento y consolidación de un movimiento historiográfico revisionista sobre la Guerra del Paraguay", en Juan Manuel Casal y Thomas Whigham (comp.), Paraguay en la historia, la literatura y la memoria. Asunción, Tiempo de Historia, 2012, pp. 391- 411.

Saitta, Sylvia, "Son memorias, el autobiográfico juego de un tímido", Boletín del Instituto de Historia Argentina y Americana "Dr. Emilio Ravignani”, Número Especial, homenaje a Tulio Halperin Donghi, Buenos Aires, 2008, pp. 155-167. 